\title{
Physicochemical Upgrading of a Biodetergent for Application in the Industrial Energy Sector
}

\author{
Charles Bronzo B. Farias 1,2,3 ${ }^{D}$, Rita de Cássia F. Soares da Silva ${ }^{2,3}$, Fabíola Carolina G. Almeida ${ }^{2}$, \\ Attilio Converti ${ }^{4, * D}$, Valdemir A. dos Santos ${ }^{1,2,3}$ and Leonie A. Sarubbo 1,2,3,*(D)
}

Citation: Farias, C.B.B.; Silva R.d.C.F.S.d.; Almeida, F.C.G.; Converti, A.; Santos, V.A.d.; Sarubbo, L.A. Physicochemical Upgrading of a Biodetergent for Application in the Industrial Energy Sector. Energies 2022, 15, 463. https://doi.org/ $10.3390 /$ en15020463

Academic Editor: Alok Patel

Received: 11 December 2021

Accepted: 4 January 2022

Published: 10 January 2022

Publisher's Note: MDPI stays neutral with regard to jurisdictional claims in published maps and institutional affiliations.

Copyright: (C) 2022 by the authors. Licensee MDPI, Basel, Switzerland. This article is an open access article distributed under the terms and conditions of the Creative Commons Attribution (CC BY) license (https:// creativecommons.org/licenses/by/ $4.0 /)$.
1 Rede Nordeste de Biotecnologia (RENORBIO), Universidade Federal Rural Pernambuco (UFRPE), Rua Dom Manuel de Medeiros, s/n-Dois Irmãos, Recife 52171-900, Brazil; charlesbronzo@yahoo.com.br (C.B.B.F.); valdemir.santos@unicap.br (V.A.d.S.)

2 Instituto Avançado de Tecnologia e Inovação (IATI), Rua Potyra, n. 31, Prado, Recife 50751-310, Brazil; rita.freire@iati.org.br (R.d.C.F.S.d.S.); fabiola.almeida@iati.org.br (F.C.G.A.)

3 Escola UNICAP Icam Tech, Universidade Católica de Pernambuco (UNICAP), Rua do Príncipe, n. 526, Boa Vista, Recife 50050-900, Brazil

4 Dipartimento di Ingegneria Civile, Chimica e Ambientale, Università degli Studi di Genova (UNIGE), Via Opera Pia, n. 15, 16145 Genoa, Italy

* Correspondence: converti@unige.it (A.C.); leonie.sarubbo@unicap.br (L.A.S.)

\begin{abstract}
In the industries across the petroleum chain and those involved in energy generation, the use of petroderivatives as fuel oils is common. To clean parts, equipment and environments contaminated by hydrocarbons, they use expensive, toxic products, bringing risks to the environment as well as to workers' health. Thus, the aim of this study was to check the stability of a biodetergent prepared using atoxic substances for large-scale production and industrial energy sector application. The relationship between volume (4 to $10 \mathrm{~L}$ ) and stirring time (5 to $10 \mathrm{~min}$ ) of the formulation at $3200 \mathrm{rpm}$ and $80^{\circ} \mathrm{C}$ was evaluated. The hydrophilic lipophilic balance (HLB), long-term stability (365 days), toxicity and efficiency of low-sulfur, viscous fuel oil removal from metal pieces and floors were investigated. The interaction among operating conditions was shown to influence the features of the product, which achieved approximately $100 \%$ stability after a stirring time of $7 \mathrm{~min}$. The emulsion HBL index varied between 4.3 and 11.0. The biodetergent maintained its physicochemical properties during its 365 days of storage and showed high efficiency, removing 100\% of the OCB1 impregnated on the metallic surfaces and floors tested. The formulation showed reliability in scale up when submitted to the study of physicochemical factors in the productive process, and safe application, by reducing risks for workers' health and environment.
\end{abstract}

Keywords: biodetergent; biosurfactant; heavy oil; scale up; emulsion; thermoelectric power plants

\section{Introduction}

There is a great industrial demand for petroderivatives, which are used by many companies and industries, such as thermoelectric power plants, to perform their activities. Thermoelectric plants commonly use heavy oils, such as low-sulfur, viscous fuel oils and diesel, to produce energy, which entails a major problem, i.e., the management of hazardous waste and dirt in the industrial environment. In addition to thermoelectric plants, other industries have the same problem, as conventional detergents cannot clean surfaces impregnated with petroderivatives; therefore, they resort to products that contain toxic, expensive and environmentally harmful petroleum-derived solvents [1-3].

The products used to clean heavy oils currently found on the market have highly toxic solvents in their compositions, which compromises the safety of employees who will be in direct contact with them when cleaning surfaces impregnated with petroderivatives, in addition to posing a great environmental risk during disposal [1,3-5]. The components of these cleaners often also corrode metal surfaces, damaging the equipment. Therefore, industries 
that use these products can pay a very high price, not only for their cost, but also for the consequences of their use, in addition to the fact that these products do not guarantee the desired cleaning and removal efficiency when used with petroderivatives $[4,5]$. Therefore, the development of ecofriendly technology has stimulated the use of natural, biodegradable detergents that are able to reduce the environmental impact as well as protect the health of workers who handle these products. Products formulated with natural raw materials, with non-corrosive properties, low cost and which are efficient at cleaning petroderivatives have been described in the literature [1-6].

A detergent is usually made up of a blend of surfactants (1-50\%), organic solvent(s), stabilizer(s) and additive(s) that are able to reduce water surface-interfacial tension [1,3]. Most chemical surfactants used in marketed cleaning and degreasing preparations are toxic and nonbiodegradable. In the last 15 years, bio-based surfactants, including the microbial ones, have been developed as an attractive and effective alternative to those already available $[7,8]$. Being prepared using renewable resources, they are atoxic, biodegradable and stable even in hard conditions [9].

Regarding toxicity, several works have already described ecotoxicity studies of biosurfactants, especially to assess the environmental application of these biomolecules. Phototoxicity studies, for example, determine the germination index, which involves the development of seeds and roots, to assess the toxic effects of biosurfactants to various types of vegetables. The larvae of the Artemia salina microcrustacean have also been used as standard indicators of the toxicity of these biomolecules $[5,6,8,10]$.

Biosurfactants are usually blended with cheap synthetic surfactants because blends of surfactants generally provide better interface properties compared with single surfactants [11]. However, even if synthetic surfactants are economically profitable, their utilization can lead to more toxic preparations. Therefore, binary systems based on nontoxic surfactants and biosurfactants are needed in a more ecological way [12]. For instance, binary blends of synthetic surfactants and tea saponin (a biosurfactant) showed enhanced interface and foaming properties compared to the single constituents [13]. A similar synergistic action of a conventional surfactant (sodium dodecyl benzene sulfonate) and an Enterobacter cloacae biosurfactant was reported by Hajibagheri et al. [11]. A blend of sophorolipid with rhamnolipid, Tween 85, sorbeth-40 tetraoleate and 2-butoxyethanol resulted in a preparation that was able to effectively disperse crude oil [14]. An oil dispersant made up of a binary blend of lauroylcholine and a biosurfactant from Starmerella bombicola displayed satisfactory crude oil-emulsifying activity in the $\mathrm{pH}$ range from 2 to 10 at salt concentrations up to $20 \%(w / v)$ [12]. A completely natural, ecofriendly biodetergent, whose formulation consisted of cotton oil, saponin and two stabilizers, was shown to be stable, non-toxic and very effective, being able to completely remove heavy oil from glassy or metallic surfaces [15]. Helmy et al. [16] successfully applied a rhamnolipid biosurfactant in the formulation of a washing biodetergent, whose stain removal efficiency was close to that of a standard detergent, thus showing potential as a promising substitute for synthetic surfactants. Arpornpong et al. [17] prepared cleaning agents at variable salinity values by changing the concentrations of a lipopeptidic biosurfactant, the natural surfactant Dehydol LS7TH (D) and butanol as a hydrophobic binder. The best formulation led to an oil-in-water $(\mathrm{O} / \mathrm{W})$ microemulsion with polyolefin containing no more than $20 \%(v / v)$ foam and $2 \%$ $(v / v)$ D. Thanks to the synergism of anionic lipopeptides with nonionic $\mathrm{D}$, the preparation was able to remove, in a jar test, $>90 \%$ of total petroleum hydrocarbons adsorbed on drill cuttings and fragments. Baharuddin et al. [18] formulated a water-based dispersant, made up of ionic liquids, which showed excellent biodegradability and facilitated the dispersal of different light and heavy petroleum samples with efficiencies in the range of 70.75-94.71\%, thus showing its potential to replace hazardous chemical dispersants in the near future.

Recently, the authors of this work developed a biodetergent that was produced with natural and non-toxic materials, formulated with a bacterial biosurfactant isolated from Pseudomonas aeruginosa ATCC 10145, with a petroderivative cleaning efficiency equal or superior to other products available on the market $[15,19]$. To scale up the production of 
the biodetergent, initially produced on a bench scale, it is essential to study the parameters of the production process, which implies considering several factors and variables that influence the final quality of the product, such as efficiency and stability under different storage conditions. In this scenario, the purpose of this study was to enable the production of the biodetergent on a large scale, in addition to verifying its long-term stability as an emulsion, as well as its application in an industrial environment.

\section{Materials and Methods}

\subsection{Formulation of the Biodetergent}

The biodetergent previously described by Farias et al. [19] was evaluated for the feasibility of production at scale and application in an industrial environment. The product was formulated with biodegradable and non-toxic components (20\% natural organic solvent, $2.0 \%$ thickening long-chain alcohol, $0.5 \%$ emulsion stabilization gum and $0.5 \%$ Pseudomonas aeruginosa ATCC 10145 biosurfactant). The components of the formulation were dissolved in water and added to the natural solvent until it reached $100 \%$ of the total mixture. The preparation was carried out under $3200 \mathrm{rpm}$ mechanical stirring (TE-139, Tecnal, Piracicaba, Brazil) at $80^{\circ} \mathrm{C}$, and the conditions of stirring time and volume were studied.

\subsection{Assessment of the Interaction between Physical Factors}

Tests were prepared separately, varying the stirring time $(5,6,7,8,9$ and $10 \mathrm{~min})$ at different volumes $(4,5,6,7,8,9$ and $10 \mathrm{~L})$ to assess the interaction between these two physical factors in the biodetergent production process, generating a total of 42 samples. They were prepared with the biodetergent produced at a temperature of $80^{\circ} \mathrm{C}$ and $3200 \mathrm{rpm}$ stirring speed, ensuring the dispersion of the formulation in immiscible phases and the stable emulsion appearance. After mixing, the batches were evaluated for stability, i.e., to analyze if there was any phase formation, for $48 \mathrm{~h}$ at room temperature. To ensure the maintenance of product efficiency, tests involving the removal of fuel heavy oil with low sulfur content and viscosity (OCB1) (Petrobras, Rio de Janeiro Brazil) from smooth and metallic surfaces were carried out to evaluate the visual characteristics and performance of the formulation. OCB1 is a complex hydrocarbon blend with 620-cSt momentum diffusivity at $60{ }^{\circ} \mathrm{C}$, a $66^{\circ} \mathrm{C}$ flashpoint, and $0.968-\mathrm{g} / \mathrm{mL}$ density at $20^{\circ} \mathrm{C}$.

\subsubsection{Determination of Biodetergent Stability}

To check biodetergent stability, each sample was tested for the extent of formulation phase separation. First, the total fluid height and the stable phase height were recorded in $\mathrm{cm}$. The stability index was defined as the ratio of stable phase height to total fluid height, multiplied by 100 and expressed as a percentage. The evaluation was performed after resting for $48 \mathrm{~h}$, and all the analyses were carried out in triplicate.

\subsubsection{Evaluation of the Efficiency of Heavy Oil Removal from the Impregnated Surface}

A portion of the surface of a glass slide with a known weight was evenly impregnated with OCB1 $(0.1 \mathrm{~mL})$. The impregnated slide portion was submerged in the biodetergent test solution for $3.0 \mathrm{~min}$. After that, the slide was dipped in distilled water to remove any excess of the test solution or destabilized residue on the surface and oven dried at $40{ }^{\circ} \mathrm{C}$ for $30 \mathrm{~min}$. After weighing, the removal index, expressed as a percentage, was determined according to the equation [14]:

$$
\text { Removal Index }=\frac{(W c-W l)}{(W c-W i)} \times 100
$$

where $W c$ is the contaminated slide weight, $W l$ is the post-wash slide weight and $W i$ is the initial slide weight.

The metal surface was washed using metallic parts (nuts) evenly contaminated by immersing them in OCB1. Contaminated portions were then submerged in the biodetergent 
test solution for $30 \mathrm{~min}$, and pieces were dipped in distilled water as described above. The removal efficiency was evaluated via visual examination [15].

\subsection{Chemical Improvement of Biodetergent}

Chemical methods were developed to help improve the characteristics of the biodetergent formulation, i.e., increase its stability (no phase formation) and reduce its viscosity to obtain a more fluid product. Thus, for chemical adaptations, different non-ionic synthetic surfactants (Span 20 and 80, Tween 80 and Triton X-100) with low hydrophilic lipophilic balance (HLB) were tested in proportions of $0.5-5.0 \%$ in a mixture of water and natural solvent to find the optimal value and concentration of surfactants to form a stable emulsion. In this sense, the emulsification index was determined as a function of HLB and surfactant content.

\subsubsection{Preparation of Emulsions}

To evaluate the HLB, the selected amount of surfactant mixture was placed in a $250 \mathrm{~mL}$ beaker, and $30 \mathrm{~g}$ of natural solvent and water were added so that the total mass of the system reached $150 \mathrm{~g}$. The mixture was stirred at $150 \mathrm{rpm}$ by means of an impeller and remained under agitation for $5 \mathrm{~min}$. After this time, $20 \mathrm{~mL}$ aliquots were transferred to test tubes to assess the emulsification index as described in the next item.

\subsubsection{Emulsification Index Determination}

The emulsification index $(E I)$, expressed as a percentage, was calculated 1 day after the preparation of the emulsions, taking into account the system total height $(\mathrm{Ht})$ and that of the emulsified one (Hem) according to the following equation [20]:

$$
E I=\left(\frac{H e m}{H t}\right) \times 100
$$

The final value of the emulsification index was determined as the average of three experiments.

\subsubsection{Final Hydrophilic Lipophilic Balance}

The final HLB balance of the binary mixture $(H L B f)$ against the tested chemical surfactants (Section 2.3) was calculated by the equation proposed by Griffin [21]:

$$
H L B f=\frac{M 1 * H L B 1+M 2 * H L B 2}{M t}
$$

where $M 1$ and $M 2$ are the masses of the first and second surfactants, HLB1 and HLB2 are their respective tabulated indexes, and $M t$ is the total mass of the mixture.

\subsection{Long-Term Stability of the Biodetergent in Adverse Environments}

Biodetergent stability tests were performed to evaluate and select the appropriate way to store the product in stock (shelf life). Samples containing $1 \mathrm{~L}$ of biodetergent produced were stored in plastic containers at room temperature $\left(28-38^{\circ} \mathrm{C}\right)$, with exposure to the sun, shade and dark environment, as well as at a controlled temperature $\left(5,30,40\right.$ and $\left.50{ }^{\circ} \mathrm{C}\right)$, using an electric stove (model TLK48, DeLeo, Porto Alegre, Brazil) and BOD incubator (model TE-371/240L, Tecnal, Piracicaba, Brazil). The samples were evaluated for 365 days, with the removal of aliquots $(50 \mathrm{~mL})$ at intervals of 30 days to evaluate the organoleptic and toxicological characteristics, their dispersing capacity for motor oil in water and their efficiency at removing petroderivatives, using either diluted $(1: 1,1: 3,1: 5$ and 1:7 $(v / v))$ or pure (undiluted) biodetergent [22]. 


\subsubsection{Evaluation of Organoleptic Characteristics}

The organoleptic characteristics of the biodetergent, i.e., visual changes, such as color, odor, homogeneity and consistency, were evaluated during the storage period. The behavior of the product in stock was investigated following the methods described by D'Leon [23], and the characteristics were categorized based on (a) color as milky, transparent and pearlescent, (b) odor as pleasant and unpleasant, (c) consistency as creamy and fluid and (d) homogeneity as hetero- and homogeneous.

\subsubsection{Toxicity Tests on Brine Shrimp as an Indicator}

Toxicity tests were carried out on microcrustacean larvae (Artemia salina) as a toxicity indicator, utilizing 1 and $2 \%$ biodetergent solutions, diluted at 1:5 or 1:10 $(v / v)$ in seawater. Larvae were tested within $24 \mathrm{~h}$ after the hatch. Tests were carried out in triplicate in $15 \mathrm{~mL}$ penicillin tubes holding ten $A$. salina larvae suspended in $10 \mathrm{~mL}$ of sea water. Larvae were examined for 1 day to determine their mortality [24].

\subsubsection{Phytotoxicity Tests on Vegetable Seeds}

The biodetergent phytotoxicity was evaluated through a static assay in terms of seed germination and root growth of cabbage (Brassica oleracea var. capitata) and tomato (Solanum lycopersicum) as previously reported [25]. The same biodetergent solutions described in the previous section were used. Sterile $10 \mathrm{~cm}$ Petri dishes containing Whatman No. 1 filter paper disks were used to determine toxicity. Each dish was symmetrically seeded with ten seeds previously washed with sodium hypochlorite, supplemented with the test solution $\left(5 \mathrm{~mL}\right.$ ) and kept at $28{ }^{\circ} \mathrm{C}$ for five days. We employed distilled water as a control. After the dark incubation period, relative seed germination, relative root elongation ( $\geq 5 \mathrm{~mm})$ and germination index (GI) were determined as follows:

$$
\begin{array}{r}
\text { Relative seed germination }(\%)=\frac{n_{\mathrm{E}}}{n_{\mathrm{C}}} \times 100 \\
\text { Relative root elongation }(\%)=\frac{L_{\mathrm{E}}}{L_{\mathrm{C}}} \times 100 \\
\text { GI }(\%)=\frac{\text { Relative seed germination }(\%) \times \text { Relative root elongation }(\%)}{100}
\end{array}
$$

in which $n_{\mathrm{E}}$ and $L_{\mathrm{E}}$ are the number of germinated seeds and the mean root length in the extract, while $n_{C}$ and $L_{C}$ are those in the control, respectively.

The mean and standard deviations of the triplicate trials were determined at every concentration.

\subsubsection{Ability to Disperse Petroderivatives in Water}

The size of the clear area appearing after introducing a detergent into a thin layer of oil deposited on a water surface is used to express its ability to disperse or aggregate petroleum-derived stains. For this purpose, sea water $(30 \mathrm{~mL})$ was placed in a Petri dish (15 $\mathrm{cm}$ in diameter), to which motor oil was added. Then, the biodetergent was added to oil at up to 1:2, 1:8 and 1:25 $(\mathrm{v} / \mathrm{v})$ ratios. The central clear area that appeared at room temperature was measured using a $300 \mathrm{~mm}$ stainless steel digital caliper after $30 \mathrm{~s}$. A larger clear diameter demonstrated greater detergent surface activity [22].

\subsubsection{Tests of Oily Washing with Metal Surfaces}

Wash tests were conducted on metal parts (nuts and washers) impregnated with OCB1 and diesel oil, previously colored with scarlet red dye to facilitate the visualization of the petroderivative and left to rest for 20 days. After the rest period, pieces were immersed in a beaker containing $30 \mathrm{~mL}$ of the biodetergent diluted at either 1:1,1:3, 1:5 or 1:7 $(v / v)$, or left 
pure (undiluted), for $30 \mathrm{~min}$. Pieces were then submerged in distilled water as previously described. Oil removal was calculated according to the equation [15]:

$$
\text { Oil removal }(\%)=\frac{M c-M w}{M c-M i}
$$

where $M c$ is the weight of contaminated metal surface, $M w$ is that after washing and $M i$ is the initial weight of the metal surface.

\subsection{Biodetergent Application in Industry}

Due to the biodetergent characteristics and its high power to remove high molar mass petroderivatives, some possible typical applications in different industrial environments were selected, especially in thermoelectric plants, because they use large volumes of fossil fuels in their process chain and in parts of the electric motor generators.

\subsubsection{Factory Floor Cleaning}

The cleaning process was carried out using two different types of flooring, a reinforced concrete floor and another composed of interlocking concrete bricks. Both surfaces received a direct application of OCB1. In both types of flooring, a specific application area $\left(10 \mathrm{~m}^{2}\right)$ was used after impregnation with this petroderivative. The floor composed of interlocking concrete bricks received an initial treatment with washed sand to remove excess OCB1 before the direct application of the biodetergent $\left(250 \mathrm{~mL} / \mathrm{m}^{2}\right)$, simulating an oily surface with old impregnation. For application of the biodetergent and better spreading of the product, brooms and squeegee-type liquid concentrators were used. The results were visually observed, as the surfaces analyzed turned clean after the application of the biodetergent.

\subsubsection{Cleaning of Parts in Thermoelectric Plants}

In some motor generators, there are intercoolers, i.e., equipment used to exchange heat with the intake air of OCB1 power generator engines. Thus, cleaning was carried out on the fins and the entire external body of the intercooler, as these are usually heavily impregnated with petroderivatives, making it difficult to exchange heat with the medium. In this specific application, compressed air was used for a better contact surface on the fin housings. Surface cleaning was also carried out with the direct application of the biodetergent on the plates present in some types of heat exchangers for OCB1 fuel engines. The results were visually observed with the cleanliness of the applied parts and surfaces.

\subsection{Statistical Analysis}

Data were statistically analyzed according to the one-way procedure in Statistica ${ }^{\circledR}$ (version 7.0) and then subjected to linear one-way analysis of variance (ANOVA). Results collected in triplicate were expressed as means \pm standard deviations. Differences were assessed using Tukey's post hoc test at a 95\% significance level.

\section{Results}

\subsection{Evaluation of Biodetergent Physical Parameters Aiming to Increase the Production Scale}

The biodetergent described by Farias et al. [19] was formulated with biodegradable and non-toxic synthetic components and a microbial biosurfactant from the bacterium $P$. aeruginosa ATCC 10145. The formulation of the biodetergent was determined from different formulations and was initially prepared using natural components, which were selected from the previous findings of our research group [15]. It was made up of (a) a natural organic solvent for maximizing heavy oil fluidization, (b) a thickening long-chain alcohol for increasing its viscosity, (c) a gum for stabilizing the emulsion and (d) the biosurfactant for removing the oil during surface cleaning. For this purpose, we selected the formulation with the lowest quantities of constituents as well as the highest stability and oil removal yield [19]. 
Based on the results previously obtained for the selected formulation, the biodetergent was evaluated according to the criteria established for the feasibility of product manufacturing and future insertion in the market. Therefore, the importance of evaluating the parameters with the greatest influence on scale up for the supply of a commercial product was noted. Thus, the stability of the emulsion was evaluated based on variations and interactions between the physicochemical parameters of the process, i.e., the agitation time and the components of the formula, considering that small changes can lead to results that are very different from those expected for product stability and rheological features. Furthermore, the product effectiveness was confirmed based on heavy oil removal in the industrial environment. The adjustments initially studied are necessary to improve the large-scale production process of the final product.

\subsubsection{Interaction among Physical Parameters}

It was possible to observe, that, since the biodetergent is an emulsion, vigorous agitation over a certain period of time is essential to obtain stability between the immiscible phases of the formulation. The physical characteristics of the product subjected to the different stirring times (5-10 min) and the volumes under study (4-10 L), such as creamy appearance, light color, mild odor, uniformity and good fluidity, were maintained in all tests (Figure 1).

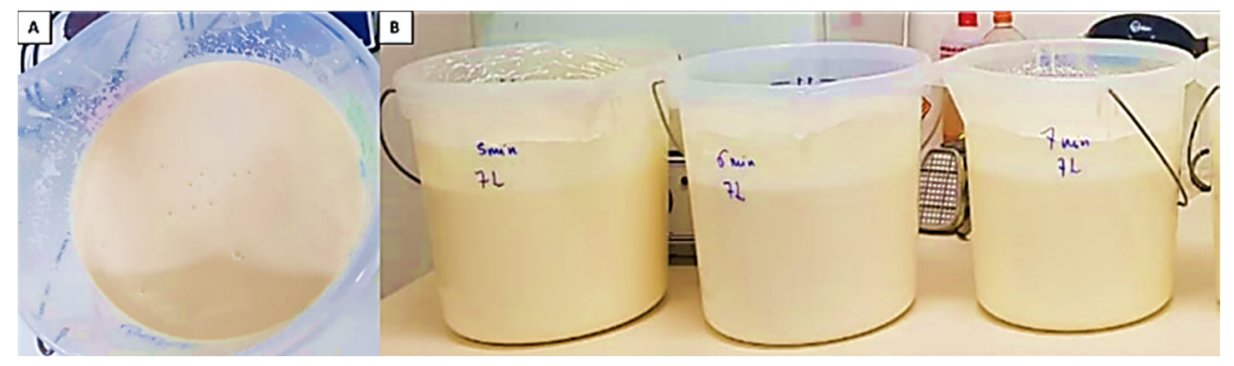

Figure 1. Illustration of biodetergent in tests carried out to assess physical parameters. The appearance, color, uniformity and fluidity were evaluated in all tests. Formulation aspect (A) right after production and (B) after tests of the volume of $7 \mathrm{~L}$ at stirring times from 5 to $7 \mathrm{~min}$.

Moreover, the maintenance of the product characteristics should also be taken into consideration in terms of resting time at room temperature, as the preparation conditions (stirring time $\times$ volume) may have a direct impact on its final features after a long rest. In this case, an emulsion is considered to be kinematically stable when the number and size of the internal phase droplets, per unit volume of continuous phase, remain constant over time, which also means that the energy value of the system and its interfacial area remain constant [26]. This aspect is important because the physical characteristics of the product are also decisive for the selection of the application form, which is related to its fluidity level. The rapid fixation of the biodetergent at its application site depends on the use of suitable techniques, such as spraying, blasting or manual application.

For all volumes tested, no phase formed after $48 \mathrm{~h}$ of rest, thus showing product stability before the process, with only a little increase in the emulsion pour point and no negative effect on product application. These aspects were observed with greater accuracy after the determination of the stability percentage for all the volumes tested over the rest period. The production tests are summarized in Figure 2. According to the graph, it can be observed that about $100 \%$ stability was ensured for all volumes tested, especially for 7 and 8 min of agitation, which reached maximum stability in practically all volumes $(4-10 \mathrm{~L})$ tested. 


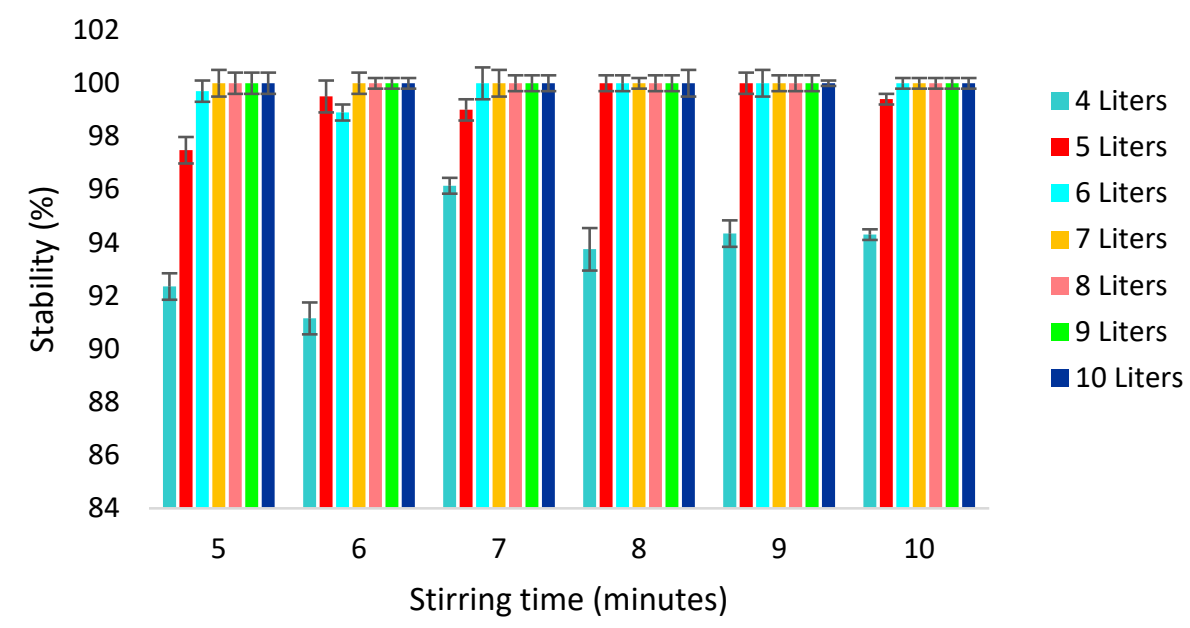

Figure 2. Stability percentages after $48 \mathrm{~h}$ of rest of the biodetergent produced at different stirring times and volumes.

The results confirmed the direct impact of the studied physical parameters on the product's visual characteristics. The stirring time showed the stronger effect independently of the volume evaluated for production and efficiency tests. Thus, 7 min of agitation at $3200 \mathrm{rpm}$ was selected as the best processing condition for the laboratory scale process for up to $10 \mathrm{~L}$.

Maintaining the pre-established physical conditions for the production process guarantees the quality and good appearance of the product. Although the conditions studied have guaranteed excellent results, a decrease in the efficiency of the biodetergent could arise. Based on the rationale that the formulation is made up of an aqueous phase (water and stabilizers) and an oil one (solvent and surfactant), and that both phases are dispersed among each other, there is an ideal interaction point between them so that one phase does not counter the action of the other. It was observed that the dispersion between both phases must occur without excess and without attenuation of the agitation speed between the different phases so as not to interfere in the heavy oil removal efficiency.

What will indicate whether a detergent is efficient or not at removing dirt is the ability to form micelles able to trap the fat inside, which is possible because the detergent is made up of an apolar part and a polar tip rather than because they form foam [27]. The biodetergent showed the complete removal of OCB1 soaked either in a glass surface (Figure 3) or in a metal one (Figure 4), suggesting that formulation effectiveness did not change with reference to the physical factors tested in the production process.

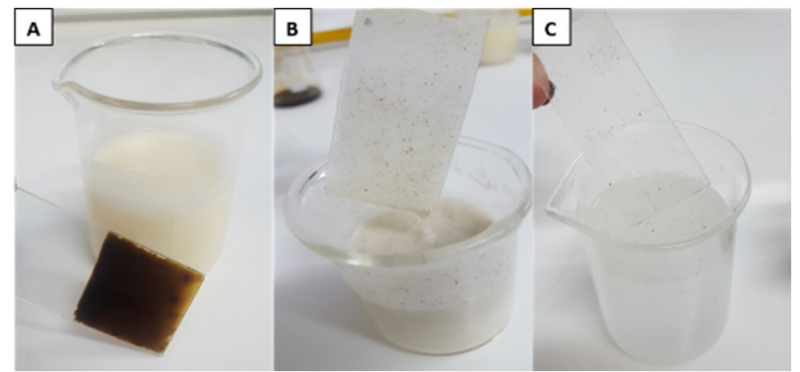

Figure 3. Illustration of OCB1 removal by the biodetergent from a glass surface. (A) OCB1 oilimpregnated glass slide. (B) OCB1 removal after submersion in the formulation. (C) Complete OCB1 removal after the slide was immersed in water. 


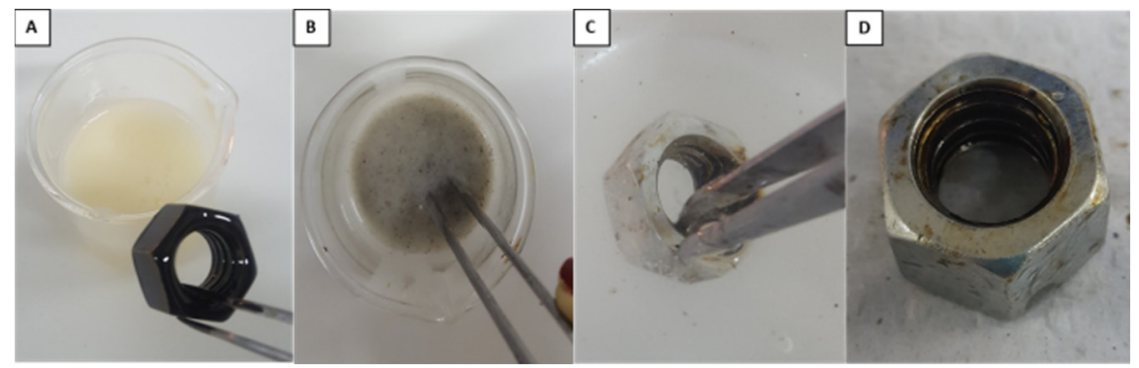

Figure 4. Illustration of OCB1 removal by the biodetergent from a metal surface. (A) Metal part contaminated with OCB1. (B) OCB1 removal after submersion in the formulation. (C) Removal of destabilized oil residues on the part after submersion in water. (D) Removal of oil on finished metallic surface.

\subsubsection{Biodetergent Chemical Evaluation and Improvement}

A chemical study was initially carried out to investigate the possibility of using a commercial and non-toxic surfactant in the final formulation to improve its characteristics.

To obtain a stable product that maintains its ability to remove oily contaminants, it is necessary to study how the emulsion breaking process occurs. Generally, these destabilization processes are influenced by the types of organic phase and surfactant, the proportion of solvents, the way the emulsion is prepared in terms of agitation speed, temperature, etc., and even by possible gases dissolved in the mixture.

To obtain an overview of the individual effects of surfactants on the stability of emulsions, tests were initially carried out disregarding the interference of other components of the formulation, such as thickening fatty alcohol and stabilizing gum. After that, it was possible to make decisions on the best way to combine the surfactants and to later use them together with the other components of the formulation.

The study of the chemical improvement of the biodetergent formulation using synthetic and non-toxic surfactants showed interesting results regarding the relationship between the emulsion stability and the binary mixture in question. The hydrophobic phase was composed of an organic solvent fixed at $20 \%$ of the total mass of the system added with water $(80 \%)$, while the surfactant content was between 0.5 and $5.0 \%$ and the HLB balance ranged from 4.3 to 11.0 .

Based on the studied surfactant systems and their determined HLB, the surfactant contents were evaluated based on the emulsification index, making it possible to estimate the best condition for the chemical improvement of the formulation. The most attractive results of the hydrophilic lipophilic balance (HLB) calculation were 5, 9 and 6 for the combinations of Span 80/Tween 80, Span 80/Triton X-100 and Span 80/Span 20, respectively. By selecting these results and displaying their respective emulsification index (EI) as function of the total surfactant content (TSC), it is possible to obtain a better comparison among the binary mixtures of the surfactants (Figure 5).

It should be remembered that HLB expresses the capacity of a surfactant to dissolve in oil or in water, leading to a water-in-oil or oil-in-water emulsion, and that small or high HLB values are typical of surfactants with a tendency to be more soluble in oil or in water, respectively [28]. Based on these considerations, the above results indicate that the Span 80/Tween 80 mixture (with an HLB of 5), despite having a higher average EI than the Span 80/Triton X-100 one (with an HLB of 9), showed a tendency to stabilize at TSC > 4\%, while the other had a tendency to increase with an increasing TSC value. On the other hand, the Span 80/Span 20 mixture (with an HLB of 6) had an average performance lower than the other mixtures at TSC $<2 \%$, but an EI value close to $100 \%$ at TSC $>3 \%$. The emulsion produced by mixing the surfactants Span 80 and Span 20 appeared as a very viscous paste and showed a satisfactory capacity for solubilizing the OCB1 oil (Figure 6A-C). It was therefore possible to initially believe that these surfactants could be the most suitable for preparing a formulation containing the other components of the biodetergent. However, after a week, the mixture started to destabilize (Figure 6D), indicating two possibilities: one 
can have an efficient but unstable product (with phase separation) or one can have a stable product but be unable to satisfactorily remove the oily contaminant.

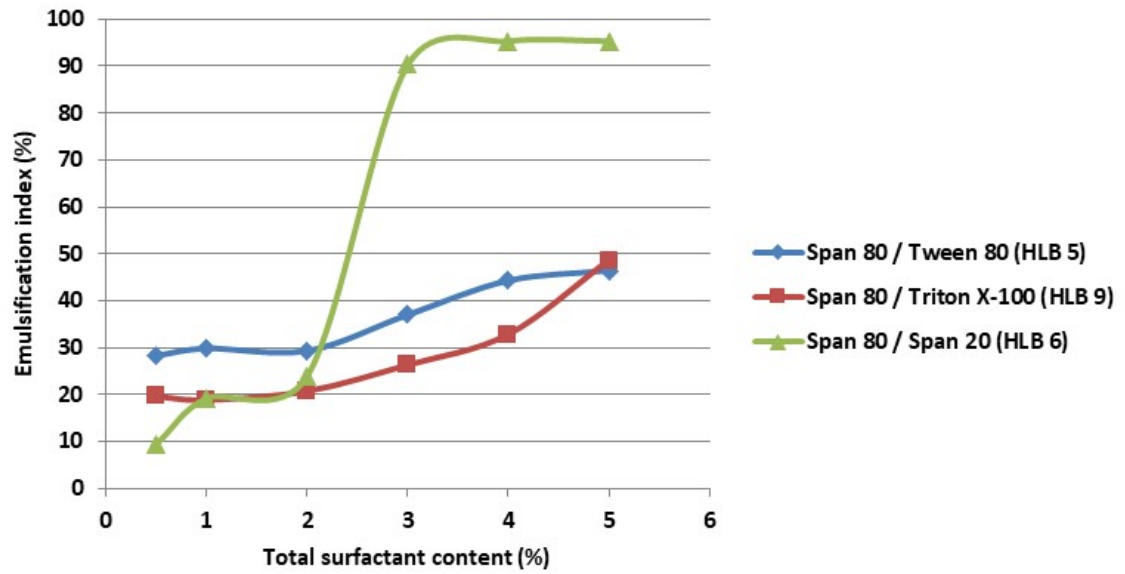

Figure 5. Graph of the values of the emulsification index of the binary mixtures analyzed as a function of the total surfactant content.
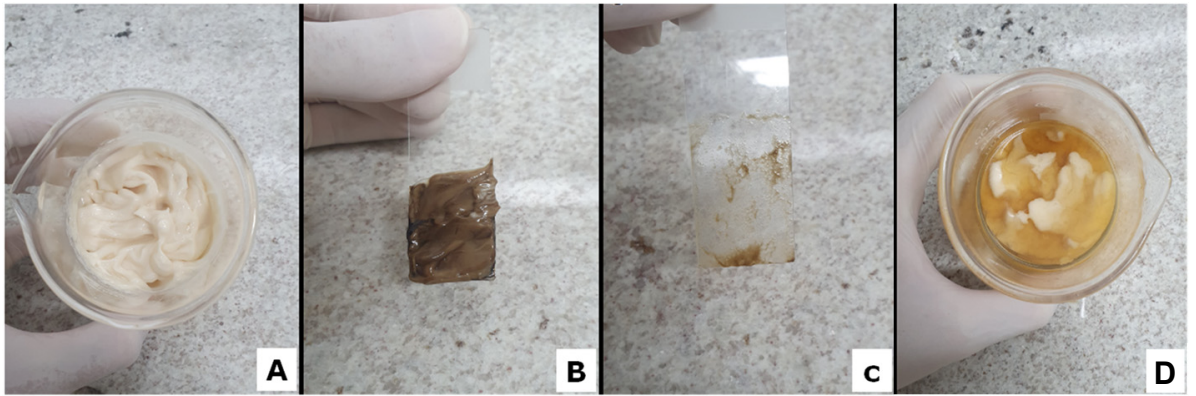

Figure 6. (A) Emulsion formed by mixing the surfactants Span 80 and Span 20 at a total surfactant content of $4 \%$. (B) OCB1 solubilization by the paste on the glass slide. (C) Residue remaining after washing with water. (D) Emulsion destabilization after one week.

These results suggested that the stable $\mathrm{O} / \mathrm{W}$ emulsion did not interact significantly with the heavy oil, but, on the other hand, a less stable emulsion managed to solubilize the hydrophobic impurity and ensure better removal. A possible solution would be to obtain a longer time for the formulation metastability to guarantee the product shelf life. Thus, vigorous agitation at a specific time to decrease the particle size of the solvent dispersed in the aqueous phase was the most effective way to ensure formulation stability. Since the chemical surfactants tested did not lead to considerable changes in the formulation, their addition would not be advisable, considering the increase in the complexity and cost of the final product and the possible addition of an extra step in the production process. It should also be taken into consideration that the process carried out for scaling up met the product characteristics according to the application needs in the cleaning and maintenance environment of the parts impregnated by oily contaminants.

\subsection{Long-Term Stability Study of Biodetergent}

\subsubsection{Assessment of Organoleptic Characteristics}

Studies of organoleptic characteristics related to the shelf life of the biodetergent were carried out over a period of 365 days. The stored biodetergent samples showed greater stability at a temperature of $5{ }^{\circ} \mathrm{C}$ for the whole period, maintaining their organoleptic characteristics of a yellowish color (characteristic color of the natural solvent), pleasant odor, fluidity and homogeneous consistency. However, in the samples exposed to the sun under controlled temperature $\left(40\right.$ and $\left.50^{\circ} \mathrm{C}\right)$, the biodetergent was unstable, showing phase 
separation after only 30 days, although maintaining a pleasant odor and fluid consistency throughout the whole period. Under the other tested conditions, i.e., in the shade, in a dark environment and at a controlled temperature of $30^{\circ} \mathrm{C}$, there was a partial separation of the phases after 240 days, although the characteristics remained unchanged during the whole shelf life.

\subsubsection{Toxicity Tests}

Atoxicity is of crucial significance when applying a product in the environment. Ecotoxicity assays are analytical procedures that make it possible to characterize the toxicity of chemical substances. Long-term stored biodetergent samples showed satisfactory results in terms of toxicity. Particularly, during a period of 365 days, the 1:5 and 1:10 (v/v) diluted biodetergent did not present toxicity to the Artemia salina larvae, even with the increase in the biodetergent concentration from 1 to $2 \%$. The mortality rate in these tests was less than $30.0 \pm 0.1 \%$, thus approaching that of the control experiment performed only with seawater $(10.0 \pm 0.2 \%)$ (Table 1$)$. In the phytotoxicity tests, the biodetergent did not show a phytotoxic effect against vegetable seeds. The germination index (GI) of the vegetable samples in the presence of the biodetergent was 89 to $100 \%$ for seeds of both species (Brassica oleracea and Solanum lycopersicum) tested at dilutions of 1:1 and 1:2 $(v / v)$ (Table 1$)$.

Table 1. Results of biodetergent toxicity tests against microcrustacean larvae (Artemia salina) and of phytotoxicity tests against seeds of cabbage (Brassica oleracea) and tomato (Solanum lycopersicum).

\begin{tabular}{|c|c|c|c|c|c|c|c|c|c|c|}
\hline \multirow{4}{*}{$\begin{array}{l}\text { Storage } \\
\text { Time } \\
\text { (Days) }\end{array}$} & \multicolumn{4}{|c|}{ Mortality Index } & \multicolumn{6}{|c|}{ Germination Index (GI) } \\
\hline & \multicolumn{5}{|c|}{ Larvae of Artemia salina } & \multicolumn{2}{|c|}{ Cabbage } & \multicolumn{2}{|c|}{ Tomato } & \multirow[b]{2}{*}{ Control } \\
\hline & \multicolumn{2}{|c|}{$\begin{array}{c}\text { Dilution of the } \\
\text { Biodetergent in Sea Water } \\
(1: 5 v / v)\end{array}$} & \multicolumn{2}{|c|}{$\begin{array}{c}\text { Dilution of the } \\
\text { Biodetergent in Sea Water } \\
(1: 10 \text { v/v) }\end{array}$} & \multirow{2}{*}{$\begin{array}{c}\text { Control } \\
\text { Sea Water }\end{array}$} & \multicolumn{2}{|c|}{$\begin{array}{c}\text { Dilution of the } \\
\text { Biodetergent in Water (1:5 } \\
v / v)\end{array}$} & \multicolumn{2}{|c|}{$\begin{array}{l}\text { Dilution of the } \\
\text { Biodetergent in Water } \\
(1: 10 \mathrm{v} / \mathrm{v})\end{array}$} & \\
\hline & $\begin{array}{c}1 \% \text { Con- } \\
\text { centration }\end{array}$ & $\begin{array}{c}2 \% \text { Con- } \\
\text { centration }\end{array}$ & $\begin{array}{c}1 \% \text { Con- } \\
\text { centration }\end{array}$ & $\begin{array}{l}2 \% \text { Con- } \\
\text { centration }\end{array}$ & & $\begin{array}{c}1 \% \text { Con- } \\
\text { centration }\end{array}$ & $\begin{array}{l}2 \% \text { Con- } \\
\text { centration }\end{array}$ & $\begin{array}{c}1 \% \text { Con- } \\
\text { centration }\end{array}$ & $\begin{array}{c}2 \% \text { Con- } \\
\text { centration }\end{array}$ & Water \\
\hline 30 & $10 \% \pm 0.2$ & $10 \% \pm 0.2$ & $10 \% \pm 0.1$ & $10 \% \pm 0.5$ & $10 \% \pm 0.2$ & $100 \% \pm 0.2$ & $98 \% \pm 0.2$ & $97 \% \pm 0.4$ & $90 \% \pm 0.3$ & $98 \% \pm 0.2$ \\
\hline 60 & $10 \% \pm 0.5$ & $20 \% \pm 0.2$ & $20 \% \pm 0.2$ & $20 \% \pm 0.3$ & $20 \% \pm 0.3$ & $97 \% \pm 0.4$ & $84 \% \pm 0.1$ & $90 \% \pm 0.3$ & $95 \% \pm 0.4$ & $94 \% \pm 0.1$ \\
\hline 90 & $20 \% \pm 0.2$ & $10 \% \pm 0.2$ & $10 \% \pm 0.5$ & $20 \% \pm 0.6$ & $10 \% \pm 0.2$ & $100 \% \pm 0.1$ & $97 \% \pm 0.2$ & $100 \% \pm 0.1$ & $95 \% \pm 0.3$ & $97 \% \pm 0.3$ \\
\hline 120 & $20 \% \pm 0.3$ & $20 \% \pm 0.1$ & $20 \% \pm 0.3$ & $20 \% \pm 0.5$ & $10 \% \pm 0.2$ & $98 \% \pm 0.2$ & $90 \% \pm 0.2$ & $92 \% \pm 0.2$ & $97 \% \pm 0.3$ & $96 \% \pm 0.4$ \\
\hline 150 & $10 \% \pm 0.4$ & $20 \% \pm 0.3$ & $10 \% \pm 0.3$ & $10 \% \pm 0.1$ & $10 \% \pm 0.5$ & $100 \% \pm 0.5$ & $98 \% \pm 0.3$ & $88 \% \pm 0.2$ & $86 \% \pm 0.1$ & $100 \% \pm 0.2$ \\
\hline 180 & $10 \% \pm 0.2$ & $10 \% \pm 0.1$ & $10 \% \pm 0.6$ & $20 \% \pm 0.5$ & $20 \% \pm 0.3$ & $87 \% \pm 0.3$ & $85 \% \pm 0.2$ & $87 \% \pm 0.3$ & $82 \% \pm 0.2$ & $100 \% \pm 0.2$ \\
\hline 210 & $10 \% \pm 0.5$ & $20 \% \pm 0.2$ & $20 \% \pm 0.4$ & $20 \% \pm 0.3$ & $10 \% \pm 0.1$ & $100 \% \pm 0.5$ & $98 \% \pm 0.3$ & $85 \% \pm 0.2$ & $82 \% \pm 0.2$ & $97 \% \pm 0.1$ \\
\hline 240 & $10 \% \pm 0.2$ & $10 \% \pm 0.1$ & $20 \% \pm 0.6$ & $20 \% \pm 0.6$ & $10 \% \pm 0.2$ & $80 \% \pm 0.3$ & $88 \% \pm 0.1$ & $96 \% \pm 0.3$ & $90 \% \pm 0.3$ & $100 \% \pm 0.3$ \\
\hline 270 & $20 \% \pm 0.5$ & $20 \% \pm 0.3$ & $10 \% \pm 0.2$ & $20 \% \pm 0.2$ & $10 \% \pm 0.4$ & $82 \% \pm 0.2$ & $86 \% \pm 0.2$ & $97 \% \pm 0.3$ & $95 \% \pm 0.2$ & $98 \% \pm 0.1$ \\
\hline 300 & $10 \% \pm 0.3$ & $10 \% \pm 0.3$ & $10 \% \pm 0.2$ & $20 \% \pm 0.5$ & $10 \% \pm 0.1$ & $100 \% \pm 0.1$ & $100 \% \pm 0.4$ & $97 \% \pm 0.1$ & $97 \% \pm 0.4$ & $100 \% \pm 0.6$ \\
\hline 330 & $20 \% \pm 0.4$ & $10 \% \pm 0.1$ & $20 \% \pm 0.3$ & $10 \% \pm 0.2$ & $20 \% \pm 0.5$ & $87 \% \pm 0.1$ & $87 \% \pm 0.3$ & $98 \% \pm 0.2$ & $90 \% \pm 0.2$ & $100 \% \pm 0.1$ \\
\hline 365 & $20 \% \pm 0.2$ & $20 \% \pm 0.5$ & $20 \% \pm 0.4$ & $20 \% \pm 0.5$ & $20 \% \pm 0.3$ & $85 \% \pm 0.3$ & $84 \% \pm 0.1$ & $98 \% \pm 0.4$ & $90 \% \pm 0.6$ & $100 \% \pm 0.1$ \\
\hline
\end{tabular}

\subsubsection{Hydrophobic Compound Dispersion Test in Water}

Tests of biodetergent samples to disperse motor oil over their 365 days of storage revealed excellent performance, with dispersion indexes above 90\% (Figure 7). In general, all the biodetergent/motor oil ratios $(1: 2,1: 8$ and 1:25 $(v / v))$ demonstrated an excellent interaction of the biodetergent as a dispersant of hydrocarbons, suggesting the possibilities for its use to bioremediate adverse environments (Figure 8).

\subsubsection{Tests of Oil Washing with Metal Surfaces}

The potential of the biodetergent to remove diesel oil and OCB1 was evaluated over 365 days, in order to check the long-term product efficiency. Tests of petroderivative removal from a contaminated surface using metal nuts and washers were carried out either with 1:1, 1:3, 1:5 and 1:7 (v/v) diluted product or with the pure (undiluted) product. These findings demonstrated the biodetergent viability as a bioproduct for cleaning processes, since the 1:1 $(v / v)$ diluted product applied to the metallic parts allowed a hydrocarbons removal above $90 \%$ and the pure one even of $100 \%$, with no difference in efficiency in all investigated storage times (Figure 9). The biodetergent also removed $100 \%$ of OCB1 oil impregnated in different types of surfaces, as showed earlier in Figures 3 and 4. 


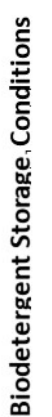

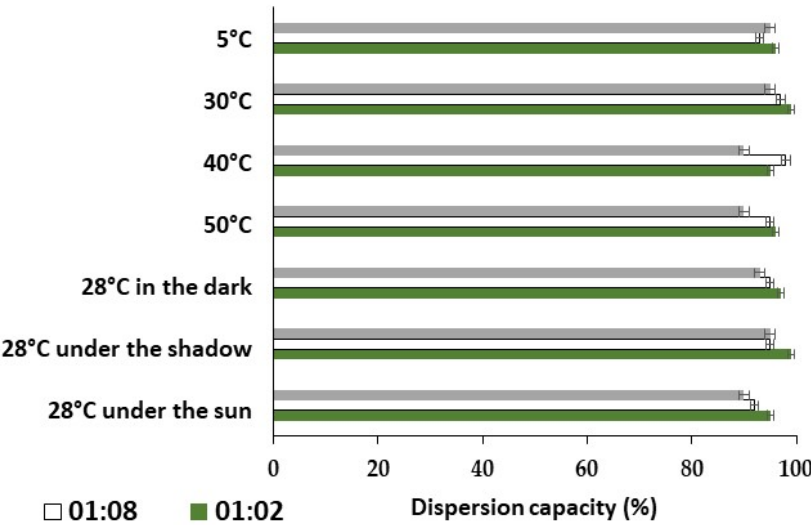

Figure 7. Percentages of engine oil dispersion by biodetergent samples stored in harsh environments for 365 days.

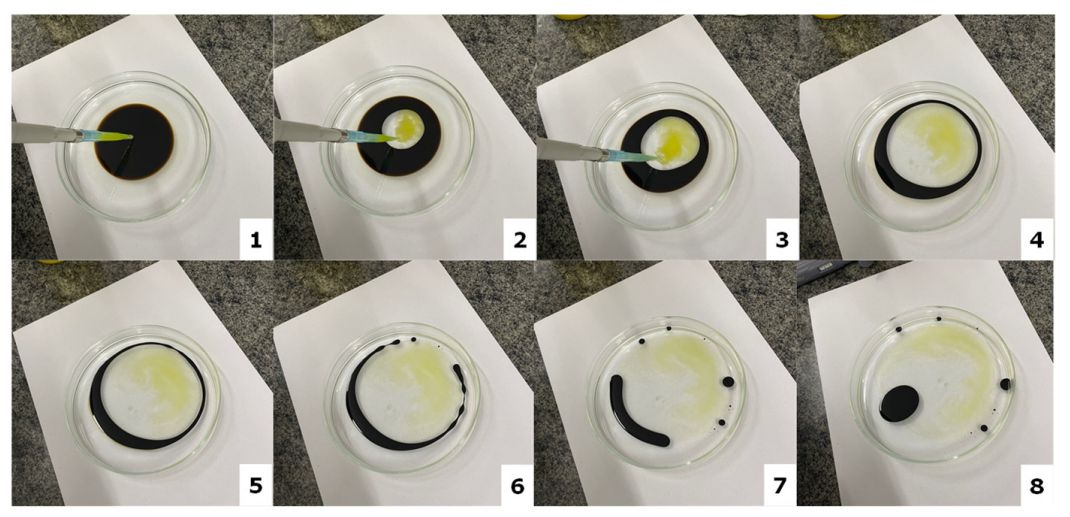

Figure 8. Illustration of the dispersion of motor oil (1-8) by the action of the biodetergent showing the sequence of evolution of the dispersing action, from the smallest diameter (2) to the total displacement (8).

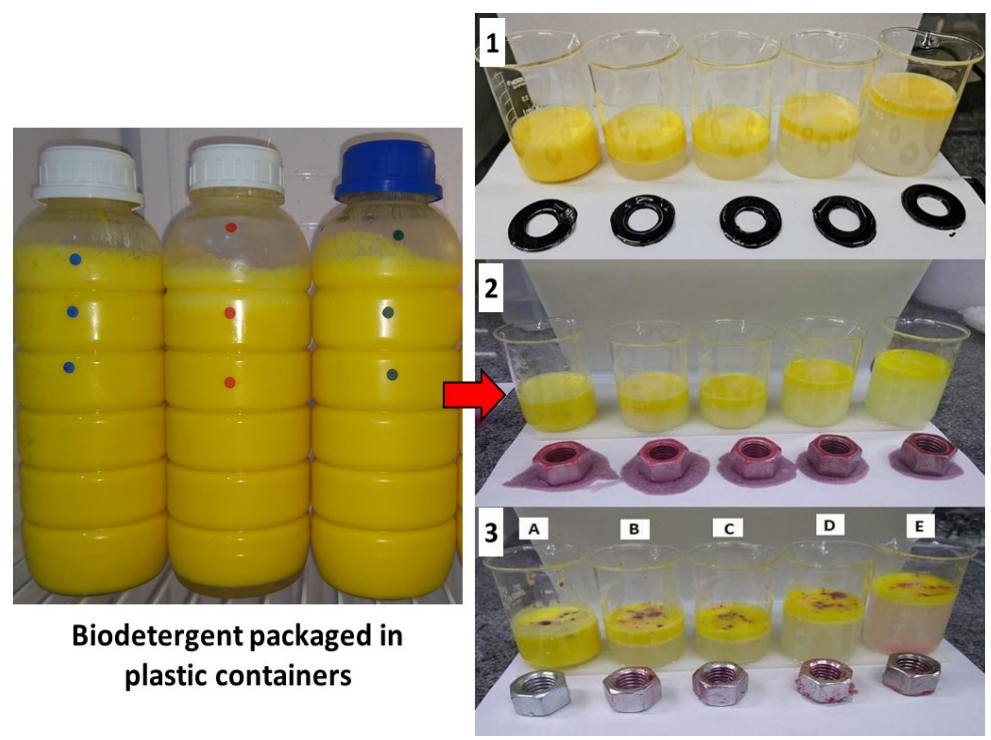

Figure 9. Appearance of biodetergent stored for 365 days. Illustration of tests of OCB1 and diesel oil removal from metallic washers and nuts by the biodetergent. 1-Tests for OCB1 oil. 2-Tests for colored diesel oil impregnated on metal parts. 3-Removal of diesel by the action of (A) pure biodetergent or (B) 1:1 (v/v), (C) 1:3 (v/v), (D) 1:5 (v/v) and (E) 1:7 (v/v) diluted biodetergent. 


\subsection{Evaluation of Biodetergent Application in Industrial Environments}

The visual examination of biodetergent application on different types of contaminated floors showed excellent decontamination performance. Figure 10 illustrates the direct application of the biodetergent for cleaning concrete floors with the aid of a squeegee-type floor liquid concentrating equipment. When applying the biodetergent to the floor, a change in color was observed as the product started its effect on OCB1, that is, adsorbing and facilitating the release of the hydrophobic compound for total cleaning. On the other hand, Figure 11 illustrates the sequence of cleaning steps of a floor composed of interlocking concrete bricks, simulating cleaning with the direct application of the biodetergent with the aid of a broom-type piece of equipment. By applying the biodetergent on the floor already impregnated with OCB1, a change in the product color occurred again, demonstrating the solubilization of the fuel oil in the biodetergent and its total removal.

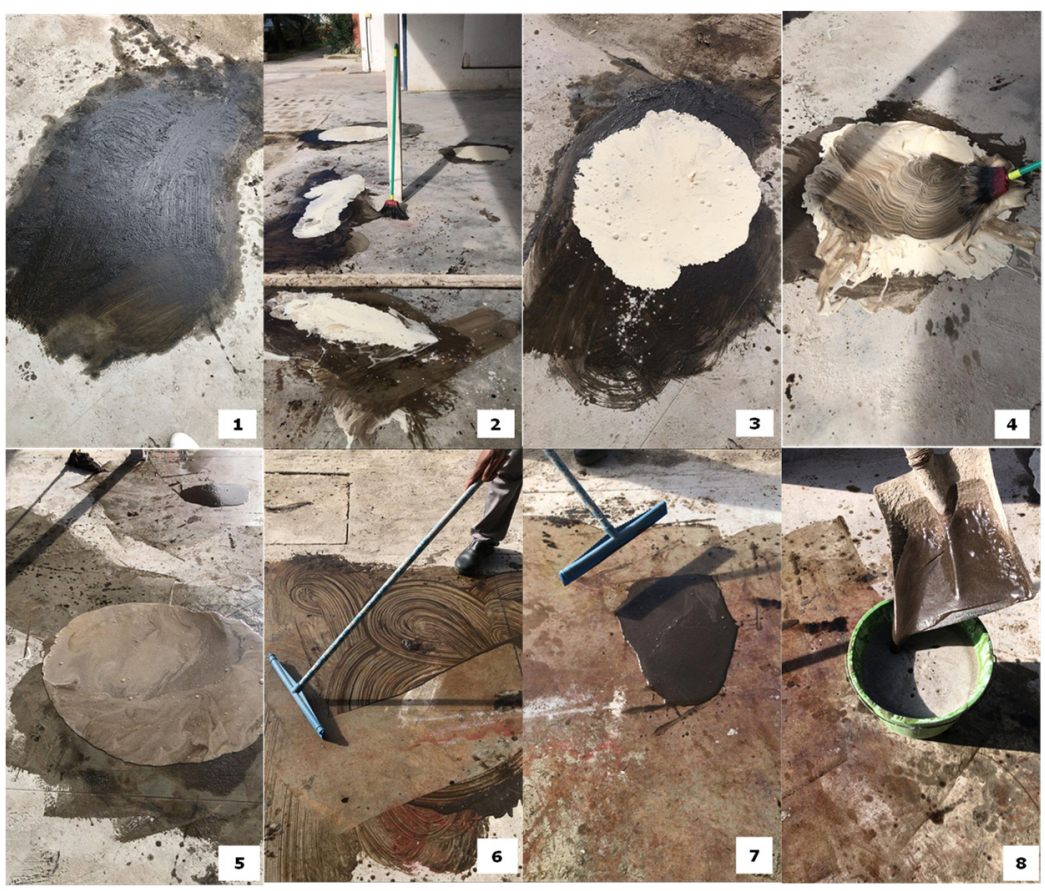

Figure 10. Sequence (1-8) of complete OCB1 fuel oil removal from reinforced concrete floor using the biodetergent.

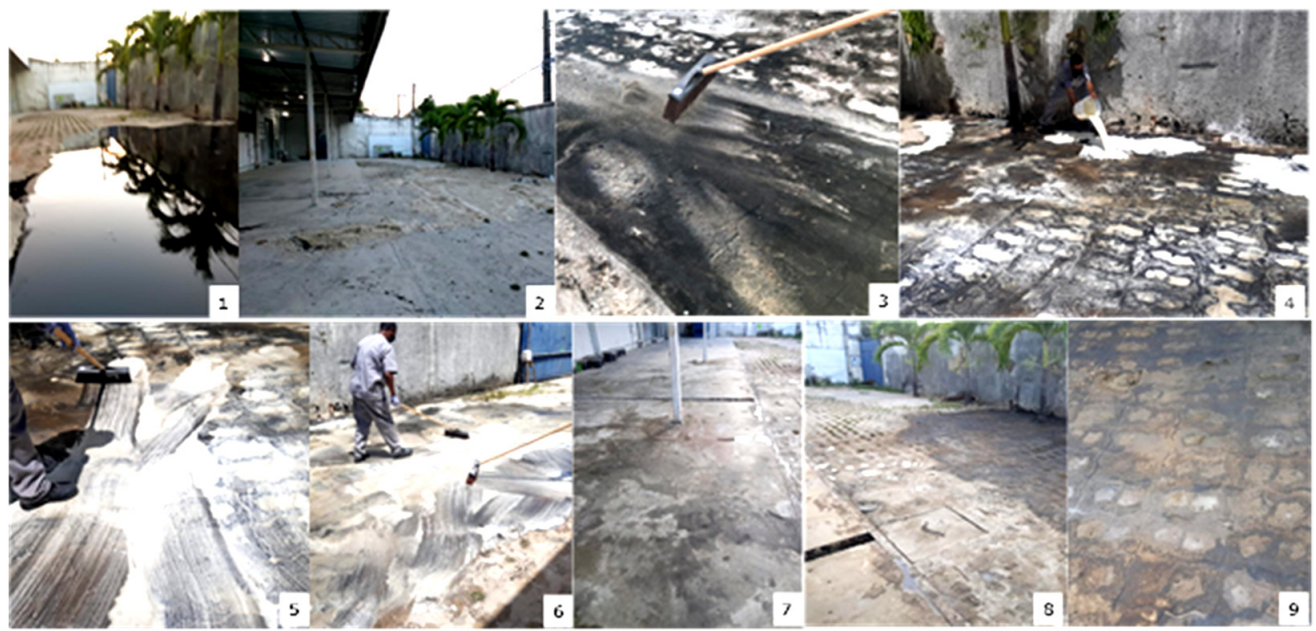

Figure 11. Sequence (1-9) of complete OCB1 fuel oil removal from interlocked concrete brick floor using the biodetergent. 
Figures 12 and 13 illustrate the application of the biodetergent directly onto metallic surfaces impregnated with OCB1. In the sequence depicted in Figure 12, the biodetergent was applied using compressed air to reach small spaces and facilitate the removal of oxidized oil from the intercooler fins. The use of the biodetergent reduced the time of cleaning for this type of equipment from $8 \mathrm{~h}$, using ineffective and toxic commercial products, to only about $10 \mathrm{~min}$, as reported by the industry workers. On the other hand, Figure 13 illustrates the successful and complete cleaning of the plate surface of a heat exchanger present in OCB1 fuel generator engines.

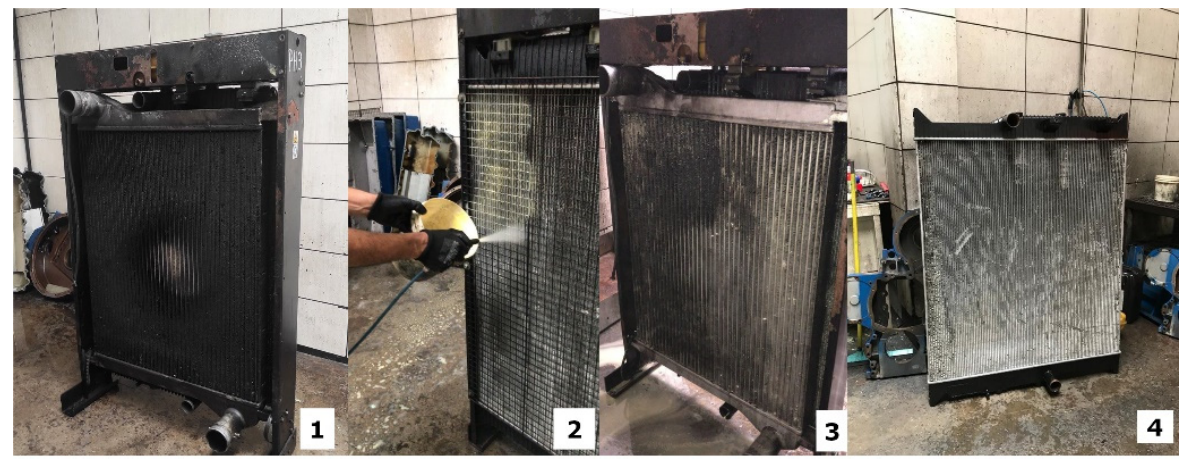

Figure 12. Sequence (1-4) of OCB1 fuel oil removal from the heat exchanger fins of thermoelectric generators applying the biodetergent with compressed air.

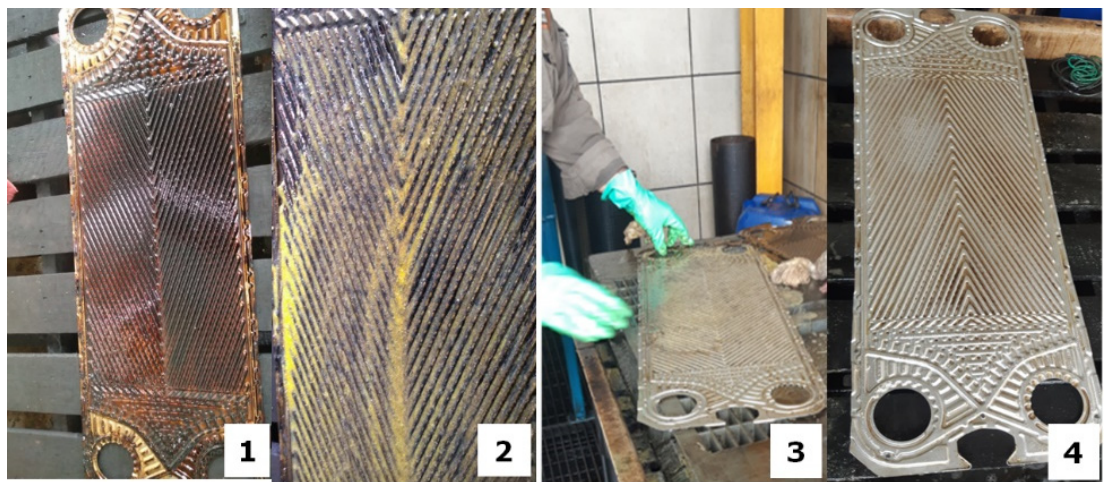

Figure 13. Sequence (1-4) of OCB1 fuel oil removal from heat exchanger plates using the biodetergent.

\section{Discussion}

In this work, the possibility of scaling up the production of an ecological biodetergent based on non-toxic and biodegradable components and a promising biosurfactant from Pseudomonas aeruginosa ATCC 10145 was investigated, aiming to implement its direct application in an industrial environment to remove the petroderivatives embedded in parts and equipment.

According to the data collected on the destabilization of the emulsions, we highlighted the importance of carrying out tests with different proportions of surfactants and with different degrees of polarity. Stability is a critical property of emulsion-type systems because it depends on their texture and microstructure, which are essential for obtaining emulsions with minimal and controlled droplets [29-31]. The destabilization can be characterized by phase separation, droplet size and viscosity. The developed formulation was found to be stable under the conditions of volume $\times$ agitation time that we investigated in this study. Tests showed approximately 100\% stability for all volumes tested, especially under 7 min stirring at $3200 \mathrm{rpm}$. The evaluation of the interaction of the physical factors involved in the biodetergent production process helped to approximately identify the conditions able to ensure the best dispersion between the droplets of the immiscible phases, allowing a greater control over the process. 
The results of this work obtained using the biodetergent formulation with the best proportion of components showed that, in addition to an adequate rotational speed, a reduction in the emulsion size or micelle formation favored physical stability. Such a finding agrees with those of Coutinho et al. [29], who produced stable creams at 4000, 10,000 and $16,000 \mathrm{rpm}$ in a rotor-stator-type homogenizer.

Chemical stability is fundamental for selecting storage conditions (temperature, light, moisture content), to choose the appropriate container material (glass, amber, clear or opaque plastic) and the type of lid, as well as to predict interactions with the product and excipients [32,33]. In this article, a comprehensive stability study was presented, where extensive information about the product was made available over a long shelf life (365 days). The product remained stable regarding its organoleptic and toxicological properties and maintained its efficiency at destabilizing complex petroderivatives. Similar studies have shown promising storage stability results for ecofriendly detergent formulations [34]. Silva et al. [35] formulated a green detergent using a biosurfactant from S. bombicola ATCC 22214 and evaluated the formulation stability after 30 days. The results were satisfactory, since the formulation did not exhibit any phase separation and kept its original color, pleasant odor and homogeneous consistency.

The biodetergent did not present toxicity to the Artemia salina larvae when diluted at 1:5 and 1:10 $(v / v)$, nor to seeds of Brassica oleracea and Solanum lycopersicum when diluted at 1:1 and 1:2 (v/v). Similarly, Rocha and Silva et al. [15] formulated a natural detergent that showed no toxicity to A. salina larvae under the same conditions. Gálvez et al. [36] performed phytotoxicity tests on onion (Allium cepa) and lettuce (Lactuca sativa) seeds with commercial surfactants considered to be detergents (Tween 80, sodium dodecyl sulfate, Aerosol 22, Triton X-100, Brij 35, Tween 80 and Glucopon 600) at different concentrations. The highest surfactant concentration $(32.5 \mathrm{~g} / \mathrm{L})$ completely suppressed seed germination. Sodium dodecyl sulfate was the most phytotoxic compound, while Tween 80 for onion and Brij 35 for both plant seeds were the least phytotoxic ones. Both nonionic surfactants and Aerosol 22 were recommended at low concentrations $(<0.65 \mathrm{~g} / \mathrm{L})$.

The dispersing ability is one of the most utilized properties to assess the quality of a detergent. In this respect, the excellent capacity of the biodetergent formulation to disperse motor oil during its 365 days of storage, revealed by dispersion indexes above $90 \%$, agrees with the results reported by Silva et al. [35] for the dispersion of a heavy fuel oil by a formulated green detergent. Rocha and Silva et al. [15] prepared a biodetergent able to disperse up to three times more hydrocarbon slick in a 1:1 ratio $(v / v)$ of detergent to oil, proving to be an excellent dispersant.

Industrial processes, which are increasingly automated and necessary for human needs, use large amounts of different hydrocarbons to enable their activities that have a strong impact on the environment. Therefore, efficient, non-toxic products capable of contributing to the environmental sustainability are well accepted in the industrial sector. The biodetergent formulation developed in this study showed high efficiency when applied in an industrial environment, in addition to preserving the well-being of workers, given that it is based on water and non-toxic natural components and has a light odor. These benefits demonstrate the possibility of replacing toxic products with biodetergents to clean machines and installations. The results obtained in this work in the cleaning of reinforced concrete floors and interlocking concrete bricks agree with the findings of Rocha e Silva et al. [15], who stressed that the application of natural detergents to clean parts and equipment contaminated by hydrocarbons or oily residues can be a more ecofriendly way of cleaning because, when making use of non-toxic, natural and anti-allergic materials, they do not cause damage to the health of employees. In addition to safety and chemical neutrality, these natural detergents proved stable and capable of completely removing the oily residues generated during industrial processes from different surfaces. Similar findings were obtained by Almeida et al. [37], who tested the application of a vegetable biosurfactant for use in cleaning motor oil and demonstrated that the biosurfactant was 
able to achieve excellent removal percentages regardless of the surfaces tested and the study conditions.

\section{Conclusions}

The understanding of the interaction between physical (stirring time and volume) and chemical parameters (combination of components) in the production of detergents stimulated the elaboration of a study aimed at the large-scale production of a biodetergent, considering that the parameterization of production control is essential to improve the system's performance and to reach a stable commercial formulation. The results showed that a vigorous agitation at a specific time, i.e., $7 \mathrm{~min}$ of agitation at $3200 \mathrm{rpm}$ in the present case, was the most effective way to decrease the particle size of the solvent dispersed in the aqueous phase and to ensure formulation stability for the scale process up to $10 \mathrm{~L}$. It is also important to say that the greatest benefits of a well-controlled production process are the reduction of industrial costs, effective management of the flow of inputs to better meet demand, balance in the use of labor and equipment, greater control over internal activities, shorter lead time of products and improvement in the level of customer service. Meeting these prerequisites is important for improving process performance. The study of production conditions on a laboratory scale allowed the development and scaling up of the process to the industrial reality, as well as its application according to the needs of parts impregnated with contaminating oils in the cleaning and maintenance environment. It is important to highlight that the field tests allowed us to safely define the best ways of application and demonstrated the efficiency of the product at an industrial level, enabling its future insertion in the market. The biodetergent achieved 100\% stability during 365 days of storage under the selected experimental conditions and was able to completely remove heavy oil impregnated on metal surfaces and floors. Furthermore, the use of microbial metabolites with decontamination capabilities and excellent properties are essential to offer an attractive biotechnological product. This makes it possible to reduce the impacts on the environment and the health of workers and to obtain consequent economic gains compared to toxic products normally used in industrial cleaning. Therefore, the biodetergent meets the criteria of efficiency, cost-effectiveness and commercial acceptability.

Author Contributions: Conceptualization, C.B.B.F. and L.A.S.; validation, C.B.B.F., L.A.S. and A.C.; writing-original draft preparation, C.B.B.F., R.d.C.F.S.d.S., F.C.G.A. and V.A.d.S.; writing-review and editing, C.B.B.F., R.d.C.F.S.d.S., F.C.G.A., L.A.S. and A.C.; visualization, C.B.B.F., R.d.C.F.S.d.S., L.A.S. and A.C.; supervision, L.A.S.; project administration, L.A.S.; funding acquisition, L.A.S. All authors have read and agreed to the published version of the manuscript.

Funding: This study was funded by the Research and Development Program from the National Agency of Electrical Energy (ANEEL) and Thermoelectric EPASA (Centrais Elétricas da Paraíba), Thermoelectric EPESA (Centrais Elétricas de Pernambuco S.A.) and Termocabo S.A. This work was also supported by the Brazilian fostering agencies Fundação de Amparo à Ciência do Estado de Pernambuco (FACEPE—State of Pernambuco Science Assistance Foundation), Coordenação de Aperfeiçoamento de Pessoal de Nível Superior (CAPES - Coordination for the Advancement of Higher Education Personnel; Finance Code-001), and Conselho Nacional de Desenvolvimento Científico e Tecnológico (CNPq-National Council of Scientific and Technological Development).

Institutional Review Board Statement: Not applicable.

Data Availability Statement: The data presented in this study are available on request from the corresponding author. The data are not publicly available due to privacy.

Acknowledgments: The authors are grateful to the laboratories from the UNICAM Icam Tech School of the Catholic University of Pernambuco (UNICAP) and from the Advanced Institute of Technology and Innovation (IATI), Brazil.

Conflicts of Interest: The authors declare that the research was conducted in the absence of any commercial or financial relationships that could constitute a potential conflict of interest. 


\section{References}

1. Rocha e Silva, N.M.P.; Meira, H.M.; Almeida, F.C.G.; Soares da Silva, R.D.C.F.; Almeida, D.G.; Luna, J.M.; Rufino, R.D.; Santos, V.A.; Sarubbo, L.A. Natural surfactants and their applications for heavy oil removal in industry. Sep. Purif. Rev. 2019, 48, 267-281. [CrossRef]

2. Ossai, I.C.; Ahmed, A.; Hassan, A.; Hamid, F.S. Remediation of soil and water contaminated with petroleum hydrocarbon: A review. Environ. Technol. Innov. 2020, 17, 100526. [CrossRef]

3. Silva, I.G.S.; Almeida, F.C.G.; Rocha e Silva, N.M.P.; Oliveira, J.T.R.; Converti, A.; Sarubbo, L.A. Application of green surfactants in the remediation of soils contaminated by hydrocarbons. Processes 2021, 9, 1666. [CrossRef]

4. Marx, A.M.; Echeveste, M.E.S.; Paula, I.C. Desdobramento da função qualidade aplicado ao projeto de um detergente sustentável. Produção 2011, 21, 724-741. [CrossRef]

5. $\quad$ Farias, C.B.B.; Almeida, F.C.G.; Silva, I.A.; Souza, T.C.; Meira, H.M.; Soares da Silva, R.C.F.; Sarubbo, L.A. Production of green surfactants: Market prospects. Electron. J. Biotechnol. 2021, 51, 28-39. [CrossRef]

6. Mousavi, S.A.; Khodadoost, F. Effects of detergents on natural ecosystems and wastewater treatment processes: A review. Environ. Sci. Pollut. Res. Int. 2019, 26, 26439-26448. [CrossRef] [PubMed]

7. Clendennen, S.K.; Boaz, N.W. Betaine amphoteric surfactants-Synthesis, properties, and applications. In Biobased Surfactants, 2nd ed.; Hayes, D.G., Solaiman, D.K.Y., Ashby, R.D., Eds.; AOC Press: Urbana, IL, USA, 2019; Chapter 14; pp. 447-469. [CrossRef]

8. Jimoh, A.A.; Lin, J. Biosurfactant: A new frontier for greener technology and environmental sustainability. Ecotoxicol. Environ. Saf. 2019, 184, 109607. [CrossRef]

9. Karthick, A.; Roy, B.; Chattopadhyay, P. A review on the application of chemical surfactant and surfactant foam for remediation of petroleum oil contaminated soil. J. Environ. Manag. 2019, 243, 187-205. [CrossRef] [PubMed]

10. Ambaye, T.G.; Vaccari, M.; Prasad, S.; Rtimi, S. Preparation, characterization and application of biosurfactant in various industries: A critical review on progress, challenges and perspectives. Environ. Technol. Innov. 2021, 24, 102090. [CrossRef]

11. Hajibagheri, F.; Hashemi, A.; Lashkarbolooki, M.; Ayatollahi, S. Investigating the synergic effects of chemical surfactant (SDBS) and biosurfactant produced by bacterium (Enterobacter cloacae) on IFT reduction and wettability alteration during MEOR process. J. Mol. Liq. 2018, 256, 277-285. [CrossRef]

12. Shah, M.U.H.; Moniruzzaman, M.; Sivapragasam, M.; Talukder, M.M.R.; Yusup, S.B.; Goto, M. A binary mixture of a biosurfactant and an ionic liquid surfactant as a green dispersant for oil spill remediation. J. Mol. Liq. 2019, 280, 111-119. [CrossRef]

13. Jian, H.; Liao, X.; Zhu, L.; Zhang, W.; Jiang, J. Synergism and foaming properties in binary mixtures of a biosurfactant derived from Camellia oleifera Abel and synthetic surfactants. J. Colloid Interface Sci. 2011, 359, 487-492. [CrossRef]

14. Song, D.; Liang, S.; Zhang, Q.; Wang, J.; Yan, L. Development of high efficient and low toxic oil spill dispersants based on sorbitol derivants nonionic surfactants and glycolipid biosurfactants. J. Environ. Prot. 2013, 4, 16-22. [CrossRef]

15. Rocha e Silva, N.M.P.; Almeida, F.C.G.; Rocha e Silva, F.C.P.; Luna, J.M.; Sarubbo, L.A. Formulation of a biodegradable detergent for cleaning oily residues generated during industrial processes. J. Surfactants Deterg. 2020, 23, 1111-1123. [CrossRef]

16. Helmy, Q.; Gustiani, S.; Mustikawati, A. Application of rhamnolipid biosurfactant for bio-detergent formulation. IOP Conf. Ser. Mater. Sci. Eng. 2020, 823, 12014. [CrossRef]

17. Arpornpong, N.; Padungpol, R.; Khondee, N.; Tongcumpou, C.; Soonglerdsongpha, S.; Sutti-ponparnit, K.; Luepromchai, E. Formulation of bio-based washing agent and its application for removal of petroleum hydrocarbons from drill cuttings before bioremediation. Front. Bioeng. Biotechnol. 2020, 8, 961. [CrossRef] [PubMed]

18. Baharuddin, S.H.; Mustahil, N.A.; Reddy, A.V.B.; Abdullah, A.A.; Mutalib, M.I.A.; Moniruzzaman, M. Development, formulation and optimization of a novel biocompatible ionic liquids dispersant for the effective oil spill remediation. Chemosphere 2020, 249, 126125. [CrossRef]

19. Farias, C.B.B.; Soares da Silva, R.C.F.; Almeida, F.C.G.; Santos, V.A.; Sarubbo, L.A. Removal of heavy oil from contaminated surfaces with a detergent formulation containing biosurfactants produced by Pseudomonas spp. Peer] 2021, 9, e12518. [CrossRef]

20. Cooper, D.G.; Goldenberg, B.G. Surface active agents from two Bacillus species. Appl. Environ. Microbiol. 1987, 53, 224-229. [CrossRef]

21. Griffin, W.C. Classification of surface-active agents by HLB. J. Soc. Cosmet. Chem. 1949, 1, 311-326.

22. Pornsunthorntawee, O.; Arttaweeporn, N.; Paisanjit, S.; Somboonthanat, P.A.B.E.M.; Rujiravanit, R.; Chavadej, S. Isolation and comparison of biosurfactants produced by Bacillus subtilis PT2 and Pseudomonas aeruginosa SP4 for microbial surfactant-enhanced oil recovery. Biochem. Eng. J. 2008, 42, 172-179. [CrossRef]

23. D'Leon, L.F.P. Stability study of cosmetic products. Cosmet. Toilet. 2001, 13, 54-62.

24. Meyer, B.; Ferrigni, N.R.; Putnam, J.E.; Jacobsen, L.B.; Nichols, D.E.; Mclaughlin, J.L. Brine shrimp: A convenient general bioassay for active plant constituents. Planta Med. 1982, 45, 31-34. [CrossRef] [PubMed]

25. Tiquia, S.M.; Tam, N.F.Y.; Hodgkiss, I.J. Effects of composting on phytotoxicity of spent pig-manure sawdust litter. Environ. Pollut. 1996, 93, 249-256. [CrossRef]

26. Tadros, T.F. Emulsion Formation, Stability, and Rheology. In Emulsion Formation and Stability; Tadros, T.F., Ed.; Wiley-VCH: Weinheim, Germany, 2013; Chapter 1; pp. 1-75. [CrossRef]

27. Química dos Sabões e Detergents Brasil Escola. Available online: https://brasilescola.uol.com.br/quimica/quimica-dos-saboesdetergentes.htm (accessed on 2 November 2021). 
28. Cheng, K.C.; Khoo, Z.S.; Lo, N.W.; Tan, W.J.; Chemmangattuvalappil, N.G. Design and performance optimisation of detergent product containing binary mixture of anionic-nonionic surfactants. Heliyon 2020, 6, e03861. [CrossRef] [PubMed]

29. Coutinho, V.P.; Sant'ana, D.B.; Santos, N.G.O.; Silva, C.A.S.; Santana, R.C. Efeito da velocidade do processo de homogeneização nas propriedades de emulsões cosméticas. J. Eng. Exact Sci. 2018, 4, 240-245. [CrossRef]

30. Feng, J.; Esquena, J.; Rodriguez-Abreu, C.; Solans, C. Key features of nano-emulsion formation by the phase inversion temperature method. J. Dispers. Sci. Technol. 2021, 42, 1073-1081. [CrossRef]

31. Santana, R.C.; Perrechil, F.A.; Cunha, R.L. High- and low-energy emulsifications for food applications: A focus on process parameters. Food. Eng. Rev. 2013, 5, 107-122. [CrossRef]

32. Rodríguez-Abreu, C. On the relationships between the hydrophilic-lipophilic balance and the nanoarchitecture of nonionic surfactant systems. J. Surfact. Deterg. 2019, 22, 1001-1010. [CrossRef]

33. Hu, Y.T.; Ting, Y.; Hu, J.Y.; Hsieh, S.C. Techniques and methods to study functional characteristics of emulsion systems. J. Food Drug Anal. 2017, 25, 16-26. [CrossRef]

34. Ansel, H.C.; Popovich, N.G.; Allen, J.L.V. Farmacotécnica: Formas Farmacêuticas e Sistemas de Liberação de Fármacos; Editorial Premier: São Paulo, Brazil, 2000.

35. Silva, I.G.S.; Almeida, F.C.G.; Rocha e Silva, N.M.P.; Casazza, A.A.; Converti, A.; Sarubbo, L.A. Soil bioremediation: Overview of technologies and trends. Energies 2020, 13, 4664. [CrossRef]

36. Gálvez, A.; López-Galindo, A.; Peña, A. Effect of different surfactants on germination and root elongation of two horticultural crops: Implications for seed coating. N. Z. J. Crop Hortic. Sci. 2019, 47, 83-98. [CrossRef]

37. Almeida, F.C.G.; Rocha e Silva, N.M.P.; Souza, T.C.; Almeida, D.G.; Luna, J.M.; Farias, C.B.B.; Sarubbo, L.A. Surfactant activity of Artocarpus heterophyllus fruit extract and application in oil removal of solid surface. Chem. Eng. Trans. 2019, 74, 1135-1140. [CrossRef] 